\title{
Fetal Alcohol Spectrum Disorders and Their Persisting Sequelae in Adult Life
}

\author{
Hans-Ludwig Spohr, Hans-Christoph Steinhausen
}

\begin{abstract}
SUMMARY
Introduction: The present review describes the different variants of Fetal Alcohol Spectrum Disorders (FASD) as a consequence of maternal alcohol abuse during pregnancy. According to international findings, some 3000 to 4000 affected newborns may be expected annually in Germany. Detection of these individuals in clinical practice is insufficient.
\end{abstract}

Method: Selective review of the literature and report of own findings based on longitudinal studies.

Results: Key features of FASD are short stature, microcephaly, various dysmorphic features, in severe cases amongst others consisting of congenital heart disease and dysplasias of the skeleton and urogenital system, varying degrees of developmental delay including mental retardation, and a positive history of maternal alcohol abuse during pregnancy. Longitudinal studies in young adulthood show that independent of the severity of FASD the key features remain associated with limitations of an independent life-style.

Discussion: Pathogenesis of FASD is not sufficiently clear and there is no causal treatment. Thus, besides prevention and information, early diagnosis, installation of fostering or adoption, and intensive psychosocial care including selection of appropriate schooling, occupational counselling and supportive care in adulthood are mandatory.

Dtsch Arztebl Int 2008; 105(41): 693-8

DOI: $10.3238 /$ arztebl.2008.0693

Key words: pregnancy, alcohol consumption, fetal period, child health, developmental disorders
Klinik für Kinder-und Jugendmedizin, DRK-Kliniken Westend, Leiter der Beratungsstelle für alkoholgeschädigte Kinder (FASD), Berlin: Prof. Dr. med. Spohr

Zentrum für Kinder- und Jugendpsychiatrie, Universität Zürich, Schweiz: Prof. Dr. med. Dipl. Psych. Dr. phil. Steinhausen ones und Smith (1)described 35 years ago a striking pattern of craniofacial anomaly and central nervous system dysfunction in 11 infants in the USA whose mothers were suffering from the effects of chronic alcohol abuse, and had continued to drink during pregnancy. Coining the term "fetal alcohol syndrome" (FAS), they documented a syndrome characterized by recognizably abnormal facial features (craniofacial dysmorphia), growth restriction/failure to thrive, delayed psychomotor development, and disturbed mental development. This syndrome gained widespread recognition following its publication in the Lancet in 1973, and soon became recognized as one of the leading causes of congenital neurodevelopmental dysfunction. In fact, this syndrome had already been described in 1968 by French authors, but had not achieved scientific recognition (2). The first scientific indication of prenatal alcohol damage was recorded in 1899 by the Liverpool prison doctor William Sullivan, who noted that women who drank excessively and had had damaged children were able to give birth to normal children in the enforced abstinence of the prison environment (3).

A wealth of published data are now available on the incidence, clinical manifestations, and long-term prognosis (4-8). Despite intensive clinical and in particular animal research, the mechanism of intrauterine alcohol damage is not established.

Numerous animal and clinical studies, in particular single reports of chromosomal, endocrine, and neurological results, have been published, but no convincing pathogenic mechanism has emerged. One interesting recent study points to apoptotic neurodegeneration secondary to a neurotransmitter disorder as a possible mechanism (9).

The aim of this review, based on a selective literature review and longitudinal studies by the authors, is to draw attention to a relatively common syndrome which is underdiagnosed due to its heterogeneous manifestations, and to its long-term effects in adulthood.

\section{Definitions and clinical picture}

The teratogenic effect of alcohol on the developing fetus comprises a spectrum of structural, neurological, cognitive, and behavioral anomalies which are summarized in the term "fetal alcohol spectrum disorders" (FASD) (10). Those children most strongly affected 
and showing all phenotypic features are described as having fetal alcohol syndrome (FAS).

Making a diagnosis of FASD in children and adolescents is clearly difficult for many doctors in practice, with the result that many cases are not diagnosed. The difficulty in making the diagnosis relates in part to the lack of a pathognomonic symptom such as that of dysmelia or phocomelia in thalidomide embryopathy, and in part to a lack of recognition by the mother or the wider family of the existence and potential fetal consequences of alcohol abuse (11). In addition, the challenging of alcohol consumption is often the subject of strong social taboos, including among doctors, leading to a failure to think of alcohol related disorders at moments where this would be appropriate. FAS is generally only recognized where it manifests floridly, such as where the mother is known antenatally to be a chronic alcohol abuser. It is far more difficult to make the diagnosis of FAS in the larger group of children with milder phenotypic features, who are suffering from so-called fetal alcohol effects (FAE). Key signs are small stature, craniofacial dysmorphia, varying degrees of developmental impairment with psychopathological symptoms, and a maternal history of alcohol abuse during pregnancy.

In addition to its clinical effect, this syndrome is also of great socioeconomic significance. A North American study from 2005 reported very high social costs arising from FASD. In addition to the individual suffering, loss of productivity and potentially lifelong costs for medical care and rehabilitation are incurred. Hence annual costs for FASD in the USA were estimated at around 4 billion dollars in 1998 (5). The syndrome was first described in Germany by Majewski (6) in the early 1990s, whose work influenced the term then current in Germany of "alcohol embryopathy."

\section{Prevalence}

There are no reliable incidence or prevalence data to date for Germany. Using international comparison and analogy with other industrialized nations, an incidence for FAS of 0.5 to 2 affected neonates/1000 live births $(12,13)$ can be assumed. Hence an annual number of 600 to 1200 neonates per year for full FAS would be expected. The number for the whole spectrum of FASD, FAS and partial FAS is significantly higher, at an estimated 4 to 6 affected children per 1000 live births (12). Around 3000 to 4000 infants are born annually with FASD in Germany. This is an enormous number, with undiagnosed cases undoubtedly in the majority. No longitudinal incidence studies are available, hence nothing can be said about a possible increase in FASD. An apparent increase in incidence has arisen via increased general awareness of the syndrome, meaning that more children are now diagnosed than in the past.

Diagnosis is further complicated by two additional factors. Many affected women nowadays suffer from multiple drug dependencies, and are abusing nicotine and tablets as well as illegal drugs on which more public attention is often focused. In addition, the majority of FASD children do not live with their parents, but in foster or adoptive families. These children have often been removed from their birth parents due to neglect or maltreatment. Foster parents are seldom made aware of the circumstances of the child's separation from his/her birth parents, namely chronic alcohol abuse. In this way, the final clue which could lead to diagnosis is often lost, particularly in older children and adolescents.

Foster parents carry a great part of the burden of this syndrome. They discover that despite great efforts on their part, the foster children are not as they would wish. These children are not only small and underweight with over $50 \%$ microcephaly, they often have eating disorders, motor restlessness, and sleep disturbances in infancy. An unusually high $60 \%$ of children are hyperactive, behaviorally erratic and uncontrolled with concentration difficulties, so that attention deficit and hyperactivity disorder is the commonest diagnosis alongside low IQ $(14,15$, e1). Although it is not always obvious, adolescents with FASD can be aggressive or depressed, and developmentally impaired in a variety of ways. For example, despite normal speech competence, they often fail to understand even simple but in particular complex situations, suffer from a lack of capacity for attachment, marginalization, and often cross prescribed boundaries to the point of violence or theft $(16, \mathrm{e} 2)$. Their educational career is often influenced by their limited basic intelligence, so that an unusually high proportion attend schools for children with special educational needs. However, because of behavioral difficulties even those with normal intelligence often end up in special schools.

\section{Diagnosis}

Early diagnosis is essential if developmental opportunities for affected children are to be optimized. The earlier US guidelines on the terminology of deficits $(17,18)$ have been replaced by a new diagnostic classification $(19,20)$, but this is not available in German translation. More recently, the category of FASD has been expanded to include alcohol related neurodevelopmental disorders (ARND), in addition to the full clinical syndrome of FAS, and that of fetal alcohol effects (FAE). Clinical examination is based on a 4digit diagnostic code, as follows:

1. Is the child underweight/small for his/her age?

2. Are there any signs of craniofacial dysmorphia?

3. Does the patient suffer any psychiatric illness which could point to CNS damage?

4. Is there any maternal history of alcohol abuse during pregnancy?

Evaluation is carried out with the help of a detailed manual, the "diagnostic guide for fetal alcohol spectrum disorders" (20). Diagnostic evaluation in each domain is ascribed a numerical value, with "unlikely" or "absent" scoring 1 point, "possible" or "unknown" 2 points, "probable" 3 points and "definite" 4 points. On the basis of these values a diagnosis is then made. 


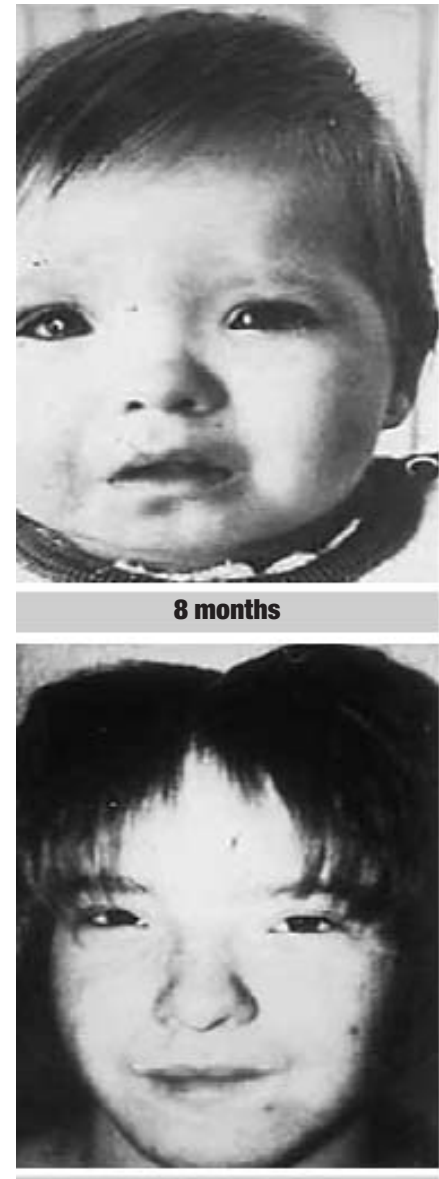

15 years

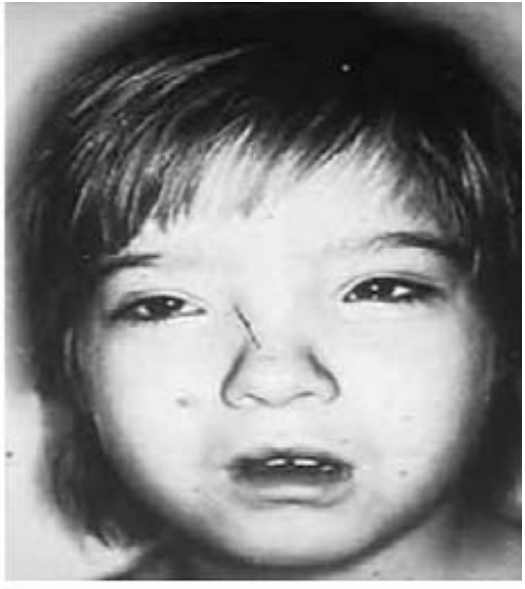

3 years

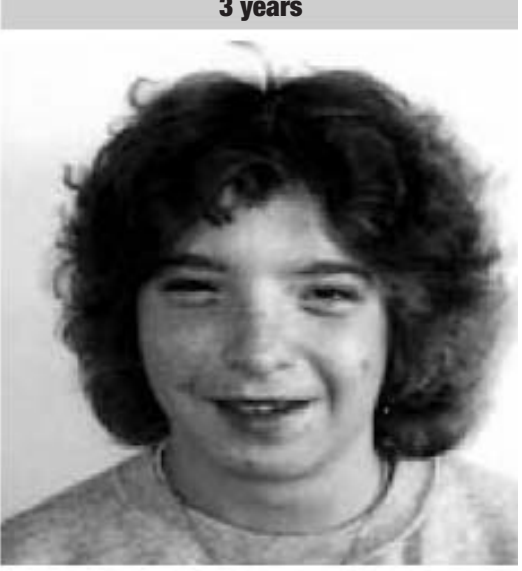

26 years

This now grown woman lived with a foster mother until the age of 18 , and then in sheltered accommodation. She is now the mother of a healthy 9-year-old daughter, lives independently, and is socially integrated and employed.

1. Small stature/low BMI: To achieve 4 points, both weight and height measurements must have been beneath the 3rd centile on at least one occasion.

2. Craniofacial dysmorphia: Three FAS-specific characteristics are noted, namely the width of the palpebral fissures, a smooth and possibly elongated nasal philtrum, and a thin upper lip.

3. Structural and functional CNS damage:

Persistent microcephaly, CNS abnormalities such as epilepsy or cerebral palsy are counted as significant structural disorders. Functional disorders are established by suitably qualified experts using a variety of neuropsychological test instruments.

4. Maternal alcohol abuse in pregnancy: According to diagnostic guidelines, there is fetal risk where the mother chronically abuses alcohol, drank constantly throughout the pregnancy, or was drunk at least once a week.

The evaluation is given by an individually derived code value. The code $4 / 4 / 4 / 4$, for example, relates to the complete picture of FAS. Partial FAS carries fewer points, for example 3/3/4/3. Craniofacial dysmorphia is particularly important in diagnosis, because it is the only one specific for FAS.
The differential diagnosis includes only a small number of other dysmorphic syndromes, which can be excluded by a clinical geneticist. These include Dubowitz syndrome, Williams-Beuren syndrome, Cornelia-deLange syndrome and velocardiofacial syndrome.

\section{Longitudinal studies}

Using the above diagnostic tools, the diagnosis can with relative confidence by the paediatrician be made in small children and schoolchildren. However, it is unclear how successfully doctors diagnose it in affected adolescents and adults $(21,22)$.

Few cohort studies have been published up to now. $(14,15,23)$. The long-term sequelae of FAS have been followed particularly closely in the United States. Streissguth et al. documented powerfully the persisting long-term sequelae for adolescents and adults. Their research cohort comprised over 400 patients diagnosed with FAS/FAE and recruited up until 1998. Of these, 90 in total were included in a cross-sectional study during adulthood (median age 25 years) (16). The most important findings were:

- $90 \%$ of adults had psychological and other health problems (predominantly ADHS in 61\% of children 

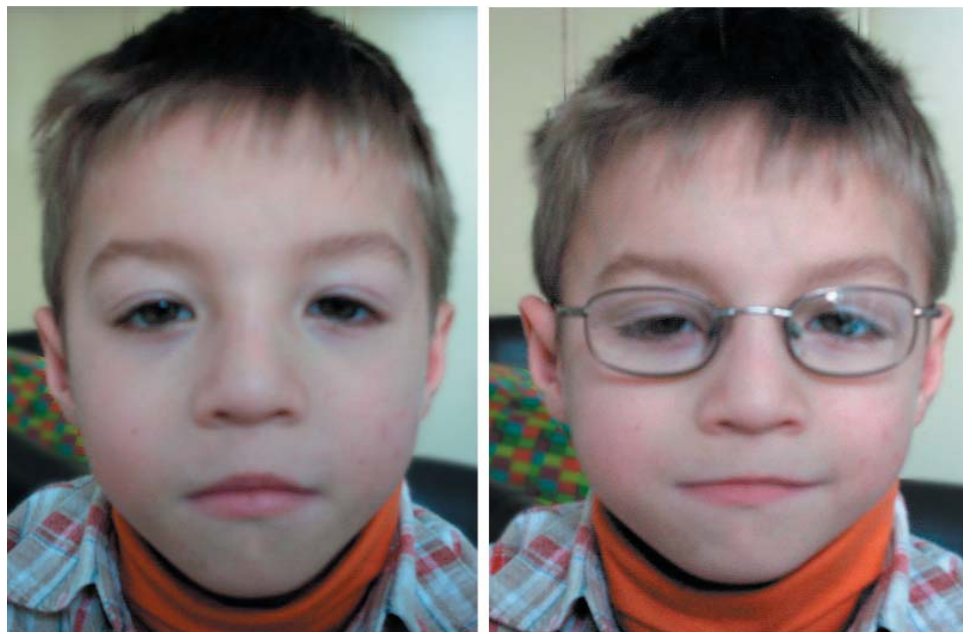

This patient is microcephalic, underweight, and of short stature. He has the typical facial features of FAS. With his foster mother's permission he will attend an anthroposophical special school because of behavioral difficulties.

and adolescents, and depression in 50\% of adults).

- $60 \%$ had experienced breaks in or a premature end to their education because of learning or behavioral difficulties.

- $60 \%$ had come into conflict with the law.

- $50 \%$ had suffered loss of liberty (23\% because of psychiatric disorders, $15 \%$ via compulsory admission for drug or alcohol dependency, and $35 \%$ because of imprisonment by the criminal justice system).

- $80 \%$ of over 21 -year-olds required personal assistance in activities of daily living. Adult FAS patients had great difficulty with working, and $70 \%$ were unemployed and lived dependent lives.

The authors also described "protective factors" (16, e2) which mitigate the extent of persistent long-term sequelae of intrauterine damage. These included living in a stable, supportive "home" for more than $70 \%$ of one's life; diagnosis before the age of 6 years, the absence of personal experiences of violence, and the acceptance of therapeutic help. Similar conclusions were drawn in Finnish and Swedish longitudinal studies (24, e3, e4).

In addition to the American and Scandinavian cross-sectional studies, our Berlin research group reported results of a cohort study of the consequences of prenatal alcohol exposure in young adults with FAS and FAE who had been diagnosed in early childhood. The 20-year follow-up permitted definitive assessment of persistent impairment and damage after childhood and adolescence (25).

This 20-year trial was able to study 37 individuals exposed to alcohol in utero. 22 of these were diagnosed with FAS and 15 with FAE. Their intelligence ranged from reduced to normal IQ. Mean follow-up was 20.5 (Standard deviation 2.8) years. The results show that despite the regression of the characteristic craniofacial dysmorphia, some signs of FAS, microcephalus in particular (head circumference below the 3rd centile), persisted in half of affected individuals. This was also true, to a lesser degree, for short stature and dystrophia, particularly in male patients.

Serious late sequelae include persistent severe and clinically significant behavioral difficulties, which, together with reduced intelligence, lead to limited vocational qualification and frequently to dependency on care in adulthood. Hence only $29.5 \%$ (11 of 37) of adults lived independent lives, whereas $70.5 \%$ (26 of 37) lived in dependent or supervised circumstances. Despite intensive and long schooling and vocational support, only $13.5 \%$ (5 of 37) of these young adults had achieved a vocational training or were able to earn their own living; $86.5 \%$ (32 of 37) of patients had no long-term employment or were unimployed.

These results are consistent with those of the American studies, although all children in our study had had the benefit of the "protective factors" previously discussed, in childhood and adolescence. It is also noteworthy that as far as measures of coping with living are concerned, no difference was found between patients with full blown FAS and those with partial FAS.

\section{Conclusions}

In summary, longitudinal studies confirm the disastrous consequences of intrauterine alcohol exposure into adulthood. These consequences are independent of the initial phenomenological diagnosis in childhood, and limit opportunities for independent living for affected individuals.

Fetal alcohol spectrum disorders are therefore a lifelong diagnosis, whose significance needs to be borne in mind by doctors if affected individuals are to receive available help for their numerous problems.

This means that primary care physicians, obstetricians, pediatricians, child and adolescent psychiatrists, and clinical psychologists must work towards early detection and follow-up for affected individuals. 


\section{Key messages}

- Fetal alcohol syndrome (FAS) is probably the commonest congenital childhood anomaly involving reduced intelligence.

- High alcohol consumption during pregnancy leads to permanent, teratogenically induced cerebral damage.

- Alcohol can also act as a behavioral teratogen, causing attention and behavioral disorders even without obvious anatomical abnormalities.

- The fetal alcohol spectrum disorders (FASD) are underdiagnosed in practice.

- The most severe type, i.e. fetal alcohol syndrome itself, is in prinicple avoidable.

- Since no causal treatment exists for FASD, early detection of affected children and education, not only for the women concerned but also in the wider population, form the cornerstone of prevention.

- The fetal alcohol spectrum disorders mean persistent, in many cases lifelong physical and psychopathological disorders for many affected patients.

Treatment is focused on the prevention of secondary dysfunctions, in particular due to reduced intelligence and associated behavioral difficulties. To this end, intensive psychosocial intervention is indicated, persisting into adulthood. An interdisciplinary approach, involving psychosocial as well as medical services, is essential.

Finally, widespread public health information about the damaging consequences of alcoholism particularly in pregnancy is important, not only for pregnant women but the population at large. This is the only way to definitive prevention, and in order to realize this, cooperation between doctors and self help groups is particularly helpful. Key societal and political agencies and the media must also be involved in these public health campaigns.

\section{Conflict of interest statement}

The authors declare that no conflict of interest exists according to the guidelines of the International Committee of Medical Journal Editors.

Manuscript submitted on 7 April 2008; revised version accepted on 3 July 2008 .

Translated from the original German by Dr Sandra Goldbeck-Wood.

\section{REFERENCES}

1. Jones KL, Smith DW: Recognition of the fetal alcohol syndrome in early infancy. Lancet 1973; 11: 999-1001.

2. Lemoine P, Harousseau H, Boteyru JP, Menuet JC: Les enfant des parents alcooliques: anomalies observées á propos de 127 cas. Quest Médicale 1968; 25: 476-82.

3. Sullivan WC: A note on the influence of maternal inebriety on offspring. J Ment Science 1899; 45: 489-503.
4. Clarren SK, Smith DW: The fetal alcohol syndrome: experience with 65 patients and a review of the world literature. N Engl J Med 1978; 298: 1063-67.

5. Lupton C, Burd L, Harwood R: Cost of fetal alcohol spectrum disorders. Am J Med Genet C Semin Med Genet 2004; 15, 127 : 42-50.

6. Majewski F: Alcohol embryopathy: experience in 200 patients. Dev Brain Dysfunc 1993; 6: 248-65.

7. Stratton KR, CJ, Battaglia FC (eds.): Fetal Alcohol Syndrome: Diag nosis, Epidemioloy, Prevention, and Treatment. Washington, DC National Academy Press 1996.

8. Spohr H-L, Steinhausen H-C (eds.): Alcohol, Pregnancy, and the Developing Child. Cambridge, UK: Cambridge University Press 1996.

9. Ikonomidou C, Bittigau P, Olney JW: Ethanol-induced apoptotic neurodegeneration and fetal alcohol syndrome. Science 2000; 287: 1056-60.

10. Hoyme HE, May PA, Kalberg WO, Kodituwakkn P, Gossage JP, Trujillo PM et al.: A practical clinical approach to diagnosis of fetal alcohol spectrum disorders: clarification of the 1996 institute of medicine criteria. Pediatrics 2005; 115: 39-47.

11. Little BB, Snell LM, Rosenfeld CR, Gilstrap NF: Failure to recognize fetal alcoholsyndrome in newborn infants. Am J Dis Child 1990 144: 1142-6.

12. May PA, Gossage JP: Estimating the prevalence of fetal alcohol spectrum disorders: summary. Alcohol Res Health 2001; 25: 159-67.

13. Sampson PD, Streissguth AP, Bookstein FL, Little RE, Clarren SK, Dehaene $P$ et al.: Incidence of fetal alcohol syndrome and prevalence of alcohol-related neurodevelopmental disorders. Teratology 1997; 56: 317-26.

14. Spohr HL, Willms J, Steinhausen HC: Prenatal alcohol exposure and long-term developmental consequences: a 10-year follow-up of 60 children with fetal alcohol syndrome (FAS). Lancet 1993; 341: 907-10

15. Steinhausen HC, Willms J, Spohr HL: The long-term psychopathological and cognitive outcome of children with fetal alcohol syndrome. J Am Acad Child Adolesc Psychiatry 1993; 32: 990-4.

16. Streissguth AP, Barr HM, Kogan J, Bookstein FL: Understanding the occurrence of secondary disabilities in clients with fetal alcohol syndrome (FAS) and fetal alcohol effects (FAE). Final Report to the Centers for Disease Control and Prevention (CDC). Seattle: University of Washington, Fetal Alcohol and Drug Unit; 1996.

17. Sokol RJ, Clarren SK: Guidelines for use of terminology describing the impact of prenatal alcohol on the offspring. Alcohol Clin Exp Res 1989; 13: 597-8.

18. Department of Health and Human Sciences: Fetal Alcohol Syndrome: Guidelines for Referral and Diagnosis. Washington, DC; 2004

19. Astley SJ, Clarren SK: Diagnosing the full spectrum of fetal alcohol exposed individuals: introducing the 4-Digit Diagnostic Code. Alcohol \& Alcoholism 2000; 35: 400-10.

20. Astley SJ, Clarren SK: Measuring the facial phenotype of individuals with prenatal alcohol exposure: correlations with brain dysfunction. Alcohol \& Alcoholism 2001; 36: 147-59.

21. Spohr HL, Willms J, Steinhausen HC:The fetal alcohol syndrome in adolescence. Acta Paediatr Suppl. 1994; 404: 19-26.

22. Streissguth AP, Aase JM, Clarren SK, Randels SP, La Due RA, Smith DF: Fetal alcohol syndrome in adolescents and adults. JAMA 1991; 265: 1961-7

23. Baer JS, Sampson PD, Barr HM, Connor PD, Streissguth AP: A 21year longitudinal analysis of the effects of prenatal alcohol exposure on young adult drinking. Arch Gen Psychiatry 2003; 60: 377-85.

24. Autti-Ramö I, Fagerlung A, Ervalahti N, Loimu L, Korkman M, Hoyme E: Fetal alcohol spectrum disease in Finland: clinical delineation 
of 77 older children and adolescents. Am J Med Genet 2006; 140A: $137-43$.

25. Spohr HL, Willms J, Steinhausen HC: Fetal alcohol spectrum disorders in young adulthood. J Pediatr 2007; 150: 175-9.

\section{Corresponding author}

Prof. Dr. med. Hans-Ludwig Spohr

Klinik für Kinder-und Jugendmedizin

DRK-Kliniken Westend

Spandauer Damm 130, 14050 Berlin, Germany

h.spohr@drk-kliniken-westend.de

(O) For e-references please see:

www.aerzteblatt-international.de/ref4108

\section{Erratum}

Correction relating to Professor Schneeweiß's conflict of interest statement in the article "Vaccination Safety Update" in issue 34-35 of 27 August 2008: The author declares that he has received honoraria for speaking from the GSK, SPMSD, and Wyeth companies. 


\section{REVIEW ARTICLE}

\section{Fetal Alcohol Spectrum Disorders and Their Persisting Sequelae in Adult Life}

Hans-Ludwig Spohr, Hans-Christoph Steinhausen

\section{E-REFERENCES}

e1. Steinhausen HC, Willms J, Winkler Metzke C, Spohr HL: Behavioral phenotype in foetal alcohol syndrome and effects. Dev Med Child Neurol 2003; 45: 179-82.

e2. Streissguth AP, Bookstein FL, Barr HM, Sampson PD, O'Malley K, Kogan J: Risk factors for adverse life outcomes in fetal alcohol syndrome and fetal alcohol effects. J Dev Behav Pediatr 2004; 25: 228-38.

e3. Autti-Ramö I: Twelve-year follow-up of children exposed to alcohol in utero. Dev Med Child Neurol 2000; 42: 406-11.

e4. Aronson M, Hagberg B: Neuropsychological disorders in children exposed to alcohol during pregnancy: a follow-up study of 24 children to alcoholic mothers in Göteburg, Sweden. Alcohol Clin Exp Res 1998; 22: 321-4. 